\section{TECHNICAL NOTES}

\section{Ultrasound mapping of long saphenous vein surface anatomy in coronary artery bypass surgery}

\section{OA Mownah, PR Middleton, RU Nair}

Department of Cardiac Surgery, Leeds General Infirmary, Leeds, UK

\section{CORRESPONDENCE TO}

Omar Mownah, E: omar.mownah@doctors.org.uk

\section{BACKGROUND}

The long saphenous vein (LSV) has been the most popular conduit for cardiac surgeons performing coronary artery bypass surgery. The traditional method of open dissection based on surface landmarks can result in morbidity (bleeding, infection, wound complications). This can be compounded in the obese patient where difficulties in locating the LSV can lead to extensive dissection and tissue damage. ${ }^{1}$ The use of endoscopic techniques to harvest the LSV is reported to reduce these morbidities but is yet to be established as routine practice. ${ }^{2}$ We describe a simple technique to augment the traditional open method by using ultrasound to mark the skin preoperatively at 3-5 points that overlie the LSV.

\section{TECHNIQUE}

Ultrasound identification of the LSV takes place in the anaesthetic room after the patient is asleep. A SonoSite ${ }^{\circledR}$ (Bothell, Washington, US) portable diagnostic ultrasound machine, which is regularly deployed for guiding central venous catheter placement, is used to identify the LSV $2 \mathrm{~cm}$ proximal to the medial malleolus, marked with an indelible pen. Two further points are identified, at the mid-calf and at $2 \mathrm{~cm}$ distal to the knee. If the dissection is to be extended into the thigh, two further points are marked.

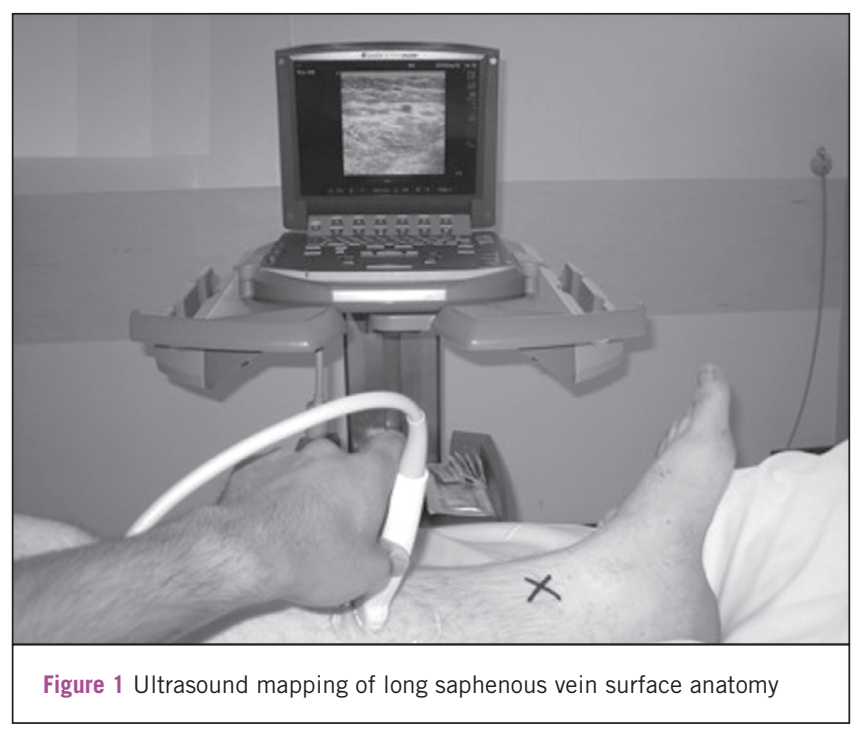

\section{DISCUSSION}

The LSV harvest has particular relevance as it offers a training opportunity to the junior members of the cardiac surgery team. We have observed minimal dissection of the tissues overlying the LSV in those cases where the vein was identified as described. In addition, there was less trauma to the cutaneous nerves and a significant reduction of subcutaneous haematoma formation. These outcomes will have a significant impact on wound healing as well as post-surgical neuralgia, particularly in obese and diabetic patient groups.

\section{References}

1. DeLaria GA, Hunter JA, Goldin MD et al. Leg wound complications associated with coronary revascularization. J Thorac Cardiovasc Surg 1981; 81: 403-407.

2. Cheng D, Allen K, Cohn W et al. Endoscopic vascular harvest in coronary artery bypass grafting surgery: a meta-analysis of randomized trials and controlled trials. Innovations 2005; 1: 61-74.

\section{Use of a purse string suture in proximal coro- nary anastomosis to reduce size mismatch between conduit and aortotomy}

Omar A Jarral ${ }^{1}$, Reza A Jarral ${ }^{2}$, Kok Meng John Chan ${ }^{1}$, Prakash P Punjabi ${ }^{3}$

${ }^{1}$ National Heart and Lung Institute, London, UK

IImperial College London, London, UK

${ }^{3}$ Hammersmith Hospital, London, UK

\section{CORRESPONDENCE TO}

Prakash P Punjabi, E: p.punjabi@imperial.ac.uk

\section{BACKGROUND}

Coronary artery bypass graft surgery commonly involves the use of the left internal mammary artery as a pedicled graft and the use of saphenous veins, radial arteries and/or right internal mammary arteries as free grafts from the aorta to the coronary arteries. ${ }^{1}$ Size mismatch may occur

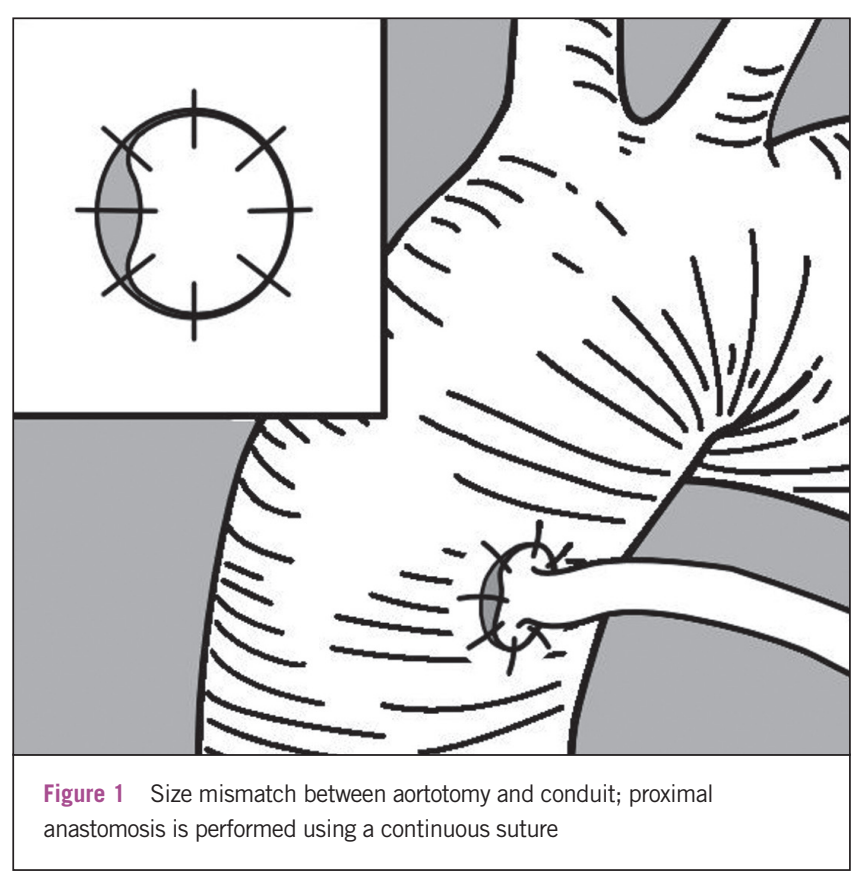




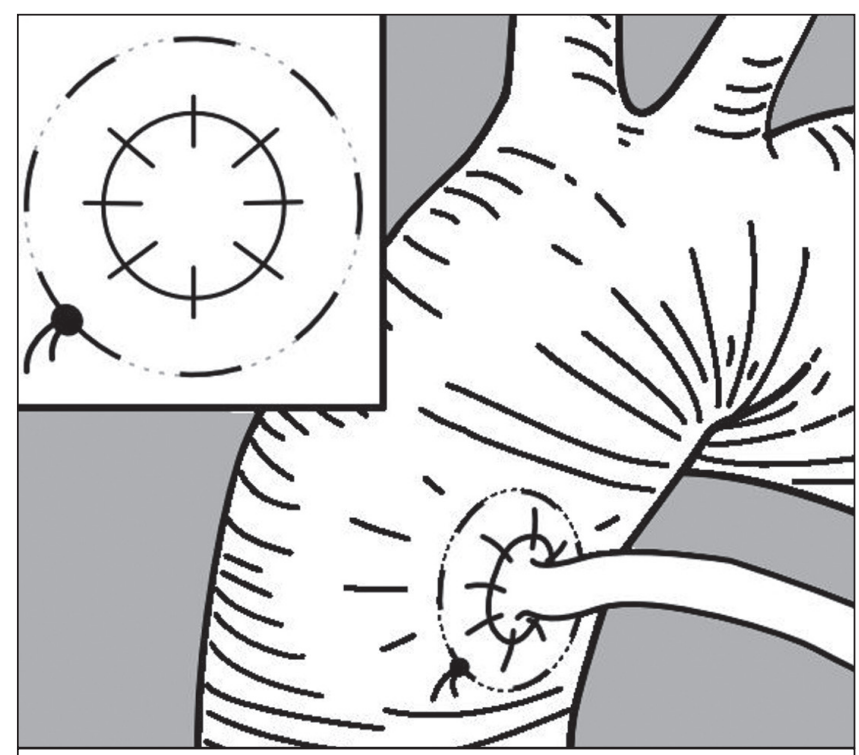

Figure 2 Purse string is placed around the aortotomy and proximal anastomosis, correcting the size mismatch

between the conduit and the aortotomy (Fig 1). It is important to stop the bleeding without compromising the anastomosis or the blood flow from the aorta to the coronary arteries through the graft. We describe a simple method to resolve this issue.

\section{TECHNIQUE}

The proximal anastomosis is performed in the usual fashion using a running suture (Fig 1). If there is generalised bleeding or ooze around the anastomosis, a separate stitch (6/0 polypropylene) is placed as a separate purse string concentrically around the aortotomy approximately $5 \mathrm{~mm}$ from the anastomotic edge. The perfusionist or anaesthetist is requested to reduce the blood pressure and the purse string is then tied, leading to a reduction of the aortotomy in a uniform style, thereby causing the bleeding or ooze to stop (Fig 2).

\section{DISCUSSION}

This simple and practical technique has been used by us successfully in several patients with size discrepancy between the conduit and the aortotomy. After tying the suture, there is a reduction in the tension at the proximal anastomosis and haemostasis is achieved. It also avoids the need to place extra sutures to secure the anastomosis, which can compromise both its immediate and long-term patency. ${ }^{2}$

\section{References}

1. Gongora E, Sundt TM. Myocardial Revascularization with Cardiopulmonary Bypass. In: Cohn LH, Edmunds LH Jr, eds. Cardiac Surgery in the Adult. 2nd edn. New York: McGraw-Hill; 2003. pp599-632.

2. Tiwari $\mathrm{A}$, Cheng KS, Salacinski $\mathrm{H}$ et al. Improving the patency of vascular bypass grafts: the role of suture materials and surgical techniques on reducing anastomotic compliance mismatch. Eur J Vasc Endovasc Surg 2003; 25: 287-295.

\section{Use of a femoral impaction grafting system in revision total elbow arthroplasty}

JD Kosy, RP Walter, VBL Conboy, SM Blake

Torbay Hospital, Torquay, UK

\section{CORRESPONDENCE TO \\ Jonathan Kosy, E: jonkosy@yahoo.co.uk}

\section{BACKGROUND}

Significant loss of humeral bone often needs addressing at a revision total elbow arthroplasty (Fig 1). A solution is impaction bone grafting using the Stryker (Newbury, UK) X-change ${ }^{\circledR}$ femoral impaction grafting system.

\section{TECHNIQUE}

Following removal of implants and cement, morsellised femoral head allograft is prepared and impacted into the proximal humerus using the distal femoral impactors. Distal impaction is achieved with the proximal femoral impactors (Fig 2). The $37.5 \mathrm{~mm}(0)$ impactor is small enough to pass into the humerus with a low risk of fracture during impaction but sufficiently large to allow subsequent passage of the definitive implant. A neocortex of impacted bone should be formed prior to cementation using

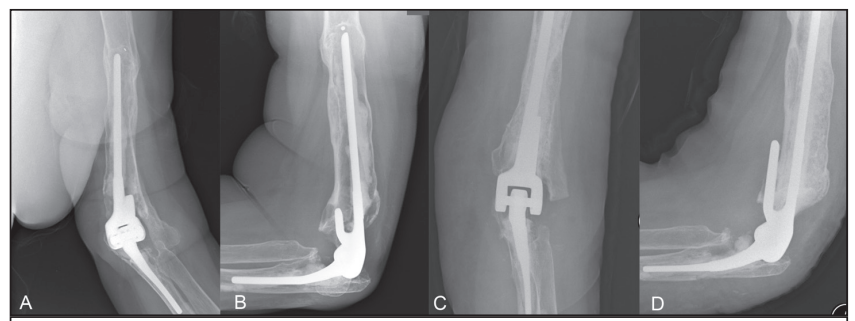

Figure 1 Radiographs of a revision case where distal humeral impaction has been necessary: (A) preoperative anteroposterior, (B) preoperative lateral, (C) postoperative anteroposterior, (D) postoperative lateral

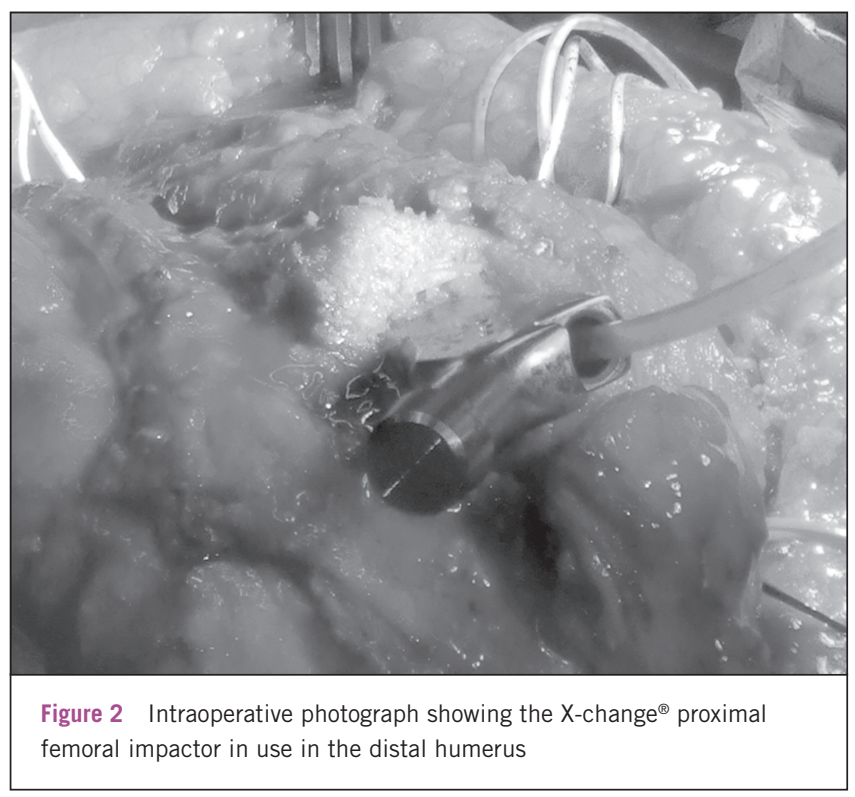

